\title{
Shakespeare en la televisión ecuatoriana del siglo XXI
}

\section{Shakespeare's influence in contemporary ecuadorian television}

DOI: https://doi.org/10.29166/tyc.v1i20.2167

\section{Daniel A. Montenegro-Sandoval}

Profesor de Historia del Arte y Diseño y Guion en el Instituto Metropolitano de Diseño. Ha trabajado como guionista y director en producciones de ficción y documentales para canales como Ecuavisa, Ecuador TV o Discovery Channel.

Correo: danielmontenegro6124@gmail.com

\section{Resumen}

La televisión ecuatoriana contemporánea carga con varios estigmas. Desde ese punto de partida, resulta difícil establecer sus lógicas y su relación con el público. Sin embargo, haciendo una revisión minuciosa de la construcción narrativa de los programas de mayor arraigo en los últimos años, podremos establecer vínculos significativos con la historia de la literatura y del arte. El presente artículo es parte de una investigación en curso que busca encontrar esos puntos de encuentro, tanto en forma como en fondo, entre algunos de los programas en la parrilla de la televisión nacional con la obra de William Shakespeare.

Palabras clave: literatura, televisión, creación, influencia, Shakespeare.

\section{Abstract}

Contemporary Ecuadorian television carries several stigmas regarding its content. However, by making a through review of some of the most popular shows and its narrative qualities, we will be able to find significant links with the history of literature. This paper is part of an ongoing investigation that seeks meeting points, both in form and in depth, among some popular ecuadorian tv shows and William Skakespeare's work.

Keywords: literature, television, creation, influence, Shakespeare. 


\section{Introducción}

Aunque el imaginario popular tiende a asociar la figura de William Shakespeare con la alta cultura, refinada e inaccesible para las grandes masas, su legado, lleno de escándalo, espectáculo, violencia, sexo y amoralidad encuentra una vía de representación más que legítima en las parrillas de programación de los canales nacionales. Mañana, tarde y noche, el espectro del autor inglés asoma su cabeza, y sus garras, ya sea en el segmento de crónica roja del noticiero de las seis como en los programas de chisme de mediodía, o el reality-show de la noche. Como el rizoma de Deleuze y Guattari (1972), que puede romperse y volverse a encontrar casi al azar, la relación entre la obra de Shakespeare y la producción televisiva ecuatoriana contemporánea, está en constante ruptura y reconciliación.

En la asociación entre el exponente más exuberante de la literatura universal y los programas de tv nacional aparece el enorme el desafío de destrabar prejuicios alrededor de ambos sujetos. Hablar de la televisión local en círculos académicos, e incluso entre la creciente clase media educada, es invocar a lo más innoble de la producción cultural. Definir que lo popular no es culto es una estrategia para marcar distinción frente a un grupo que el propio diccionario define como "gente común y humilde", "de menor categoría" (Yépez, 2012).

Esto, sumado a la gigantesca sombra de Shakespeare, de tal magnitud que Harold Bloom afirma en El Canon Occidental que tenemos una deuda no solo con su literatura sino, en gran parte, con la creación de nuestras propias capacidades cognitivas (Bloom, 1994), se hace apa- rente una distancia insalvable entre ambos.

Sin embargo, aún en esa distancia e inconsciencia mutua, las más elevadas reflexiones de Hamlet, Yago o Falstaff, tienen su espejo en Mi Recinto, en Combate o en Ecuador Tiene Talento. En una encuesta realizada por Elizabeth Vallejo, $R e$ presentaciones Sobre la Población Afroecuatoriana en la Comedia de Televisión Ecuatoriana, el grupo consultado rechazó los contenidos de Combate, Calle 7 y $B L N$ debido a que los consideran de pésima influencia para niños y niñas, ya que los participantes discuten, pelean y se insultan. El mismo grupo, por su parte, calificó a Vivos como un programa divertido (Vallejo, 2016, p. 80).

Hablar de Shakespeare, como se mencionó inicialmente, es hablar de lo políticamente incorrecto, de lo vulgar, del insulto, la pelea. Pero también es hablar del goce. En ambos casos, pilares fundamentales de la televisión ecuatoriana desde hace más de 20 años. Salvo pequeñas y poco memorables excepciones, el grueso de los programas de producción autóctona tiene como eje el escándalo y el entretenimiento, el desborde de las pasiones y la burla despiadada. Melodramas cargados de prejuicios, comedias con doble sentido, tensión exagerada y mucho lenguaje popular.

Y no hace falta, para esto, que los libretistas y creativos ecuatorianos tengan un amplio conocimiento del lenguaje en las tragedias o comedias del genio renacentista. Es la jerga cotidiana del barrio, el mito del amor imposible, los roles de género, el hermano abusivo, el psicoanálisis, o los nombres importados lo que trae a colación permanentemente al hombre que, como lo define Stephen Marché, lo cambió todo. "Shakespeare ha cam- 
biado tu vida incluso si nunca lo has leído" (Marché, 2014, p. 10).

Claude Levi-Strauss (1978), indica que "lo que esperamos en un diccionario es encontrar el significado de una palabra a través de otras palabras". Así como no sabemos siempre el origen de las palabras que usamos, o las ideas que defendemos, Shakespeare atraviesa el imaginario popular y se transforma, se conserva y es susceptible de comparación, tal como lo plantea Roman Jakobson con respecto a posibles adaptaciones inverosímiles de otras obras universales como la Ilíada, la Odisea y la Divina Comedia, en sus conferencias sobre Lingüística y Poética.

Por muy absurda que parezca la idea de hacer la Ilíada y la Odisea en dibujos animados, ciertos rasgos estructurales del argumento se conservarán a pesar de la desaparición de su forma verbal. La cuestión de que las ilustraciones de Blake a la Divina Comedia sean o no adecuadas es prueba de que las diferentes artes son susceptibles de comparación. (Jakobson, 1981)

Por su parte, en El Placer del Texto, Roland Barthes dice del escritor que es aquel que juega con el cuerpo de su madre para glorificarlo, embellecerlo, o para despedazarlo, llevarlo al límite de sólo aquello que del cuerpo puede ser reconocido: irá hasta el goce de una desfiguración de la lengua, y la opinión lanzará grandes gritos pues no quiere que se "desfigure la naturaleza" (Barthes, 1974, p. 61). Es pertinente entonces, según Barthes, desacralizar la figura de Shakespeare (y todos los genios del canon artístico occidental, incluidos los críticos) y su obra, visibilizando su aporte a la cultura popular, en esos pedazos que quedan.

David Simon, creador de la serie americana The Wire, se pregunta “¿Cómo van a articularse los relatos de forma segura y consistente si no es utilizando los paradigmas más básicos del bien y el mal, de héroes $\mathrm{y}$ villanos, y creando personajes simples? Dónde, sino en tramas que sean accesibles hasta para el más ignorante e indiferente de los espectadores" (Álvarez, 2013, p. 1).

Shakespeare, como David Simon en The Wire, pero también David Reinoso en Vivos, o Peky Andino en Secretos, y José Delgado en En carne Propia, crearon obras accesibles hasta para el más ignorante e indiferente de los espectadores donde, finalmente, las historias se reducen a un combate grotesco entre el bien y el mal, una poética del conflicto. Cosa distinta, y ciertamente rebatible, es esperar de ellos la creación de modelos ejemplares de las buenas costumbres pues, bien apunta Bloom al afirmar que "leer a los mejores escritores, no nos convertirá en mejores ciudadanos". (Bloom, 1994)

\section{La representación de lo popular}

La flexibilidad de la obra de Shakespeare es casi infinita. La aparición del fantasma de Sharon, los asesinatos a sangre fría de En Carne Propia, o la inocencia inicial del amor en La Pareja Feliz, son adaptaciones de Hamlet, Tito Andrónico y Romeo y Julieta. Pero no solamente porque replican sus estructuras mitológicas sino y, sobre todo- porque "los personajes de Shakespeare aceptan estar empapados de su contexto social e histórico" (Bloom, 1994).

Los símbolos patrios y republicanos como el himno nacional, el escudo e incluso los héroes independentistas, nunca terminan de ser suficientemente cercanos a las realidades heterogéneas de un pueblo diverso, que se siente más próximo a la fauna cotidiana del barrio. 
Entonces, podemos decir que el Ecuador es un país que sigue debatiendo sus símbolos. En su texto sobre ciudadanía e identidad, Simón Pachano afirma que "buscar una definición de identidad ecuatoriana no solo resulta complejo, sino inútil, porque desconoce la diversidad" (Pachano, 2003).

Pachano, continúa problematizando la identidad y, por medio de ella, a los símbolos que emplea para su imposible consecución:

Entonces la identidad nacional ya no puede ser entendida como una esencia estable, capaz de ser reconocible ni detectable de forma pura y clara. Hoy decir soy ecuatoriano supone un enorme problema de definición sobre qué se entiende por ese ser ecuatoriano (Pachano, 2003).

En ese escenario, la noción de lo popular logra camuflarse y admite contradicciones en la construcción de los símbolos de esa identidad amorfa e incompleta.

En el estudio que hace Sandra Yépez sobre la estética en la obra de Delfín Quishpe, se define a lo popular como la expresión del pueblo. Un pueblo vinculado a lo bajo y lo pobre en contraposición de la llamada "alta cultura" (Yépez, 2012).

Ahora bien, esta disputa tiene un matiz significativo. Mientras ese pueblo, bajo y pobre, tiene un acceso sumamente limitado a la alta cultura (bibliotecas, museos o salas de cine-arte) los sujetos de las élites culturales e intelectuales sí conviven con las expresiones populares.

Las televisoras de escala nacional, cooptadas desde siempre por las burguesías abanderadas de la alta cultura, son el espacio medular donde se construyen los relatos que definen la escala de valores de nuestra sociedad y sus relaciones de poder, adaptándose, sin embargo, a las formas de lo popular.
En esa medida, las fuerzas dominantes siguen condicionando el discurso, tal como lo hicieran en el siglo XVI ya que, si bien Shakespeare creó una poesía inigualable, sus motivaciones también respondieron a las circunstancias del poder político y financiero de su época. Así como los creadores de El Combo Amarillo, Sharon o Vamos Con Todo, "Shakespeare dependía necesariamente del patronazgo y la protección de los aristócratas" (Bloom, 1994, p. 55).

El pensamiento dominante sostiene que solo algunos sectores merecen el privilegio de tener cultura, mientras que al resto los deja navegando en la incultura del arte popular. Pero cuando se cae en el reduccionismo binario entre cultura e incultura se corre el riesgo de no detectar las redes invisibles que se tejen entre lo popular y lo culto.

Lo popular se permite tomar historias, objetos y sentidos de la llamada alta cultura, para crear con ellos nuevas expresiones, propias, originales y evidentemente grotescas (Yépez, 2012).

Ese pueblo se apropia de las intermitentes apariciones de símbolos porque se siente reconocido. Sin embargo, no es extraño encontrar en la televisión contenidos que apelan a las lógicas y valores de lo popular mientras perpetúan las estructuras sociales de dominación, tal como Zizek sostiene: "la lógica misma de la legitimación de la relación de dominación debe permanecer oculta para ser efectiva" (Zizek, 2003, p. 1).

En esa convivencia conflictiva hay cabida para absolutamente todo, particularmente para la contradicción. Es el caso del noticiero 24 Horas de Teleamazonas, que convive con En Corto, un espacio de humor político y farándula. Los presentadores del noticiero, tienen que mudar su 
postura cultísima, acartonada y protocolar, para compartir el entusiasmo sarcástico del chisme político durante ese brevísimo segmento, creando un habitus en el que todo se mezcla con todo. El habitus es una manifestación simbólica cuyo sentido y valor dependen tanto de los que la perciben como del que la produce.

De gustos y colores no se discute: no porque todos los gustos están en la naturaleza, sino porque cada gusto se siente fundado por la naturaleza -y casi lo está, al ser habitus-, lo que equivale a arrojar a los otros en el escándalo de lo antinatural. La intolerancia estética tiene violencias terribles. La aversión por los estilos de vida diferentes es, sin lugar a dudas, una de las barreras más fuertes entre las clases (Bourdieu 2000, p. 54).

Afortunadamente, estas barreras de aversión por el estilo de vida del otro son parcialmente rotas en la televisión ecuatoriana. Lo hizo Shakespeare durante aquellas representaciones en el teatro The Globe de Londres, donde asistían aristócratas y esclavos, tal como lo hace Flor María Palomeque con su personaje La Mofle, que es capaz de hacer una presentación en Flor de Bastión un día, pero al siguiente repetir su monólogo para el Alcalde de Guayaquil.

En el Ecuador del siglo XXI toda celebridad tiene que pasar por lo popular. No hay tal cosa como los intelectuales, científicos o poetas célebres, y lo popular se hace popular en la televisión. Según el Instituto Nacional de Estadísticas y Censos (INEC; 2012), la población ecuatoriana ve, en promedio, tres horas diarias de televisión y nueve de cada diez hogares cuentan con un televisor, lo que lo mantiene como el medio de comunicación más utilizado y eficaz en el país.

Esta penetración de la televisión en las familias ecuatorianas se ha tratado re- currentemente como un mal social. Pero esta acusación, con frecuencia reproducida desde el pedestal moral de la academia, tildando a la televisión de caja boba, hecha por y para ignorantes, no es más que una postura que busca ocultar las dinámicas sociales del país. "Este hecho envenena la vista, ocultémoslo", dice Ludovico en Othello, anticipándose a la vergüenza de las gentes cultas que niegan su contacto con lo popular.

Geovanny Panchi hace una reflexión respecto a las narrativas más polemizadas de la televisión.

De alguna forma, En Carne Propia, junto con medios impresos como Diario Extra, representa la imagen misma de aquello que las y los defensores del "deber ser" periodístico y la ética liberal de los medios consideran como inadecuado, antiético, violento y destructor de los criterios valiosos para la convivencia y la función social de los medios de comunicación. Estos espacios son la oposición frontal, desfachatada y hasta maliciosa de todo lo patriótico, sensible y benefactor de la cultura y los altos intereses sociales que deben guiar al periodismo. (Panchi, 2014, p. 75)

Por el contrario, afirma Panchi, son precisamente estos relatos los que realmente trabajan como espejos de la realidad.

En Carne Propia se ha especializado en exponer sujetos salidos completamente de las tradiciones mediáticas, padres y madres de familia, vecinos de barrios populares, peluqueros, taxistas, consumidores de drogas, delincuentes comunes, vendedores ambulantes, vigilantes de seguridad, enfermos mentales y un largo etc. de personas que en otras publicaciones y otros contextos apenas son presentados (Panchi, 2014, p. 75).

¿Y no es, acaso, la gran literatura universal, el cine clásico, la música decimonónica, donde más y mejor se han re- 
presentado a los canallas, los parias, los excluidos de este mundo? En Shakespeare, el bufón es una figura recurrente y fundamental, porque su condición de payaso y su disfraz le permiten decir lo que a ningún otro le es aceptado. El Loco del Rey Lear es tal vez el único que confronta, e incluso insulta, a su rey para que este caiga en cuenta de su estupidez.

Shakespeare dice del teatro, y por extensión se podría decir de la televisión, que su fin es, al principio y ahora, era y es, por decirlo así, sostener el espejo a la Naturaleza, mostrando a la virtud su propia figura, al vicio su propia imagen, y a la época y conjunto del tiempo, su forma y su huella.

Por lo tanto, aquellos que basan sus críticas a la programación de la televisión nacional en la calidad o superficialidad de sus contenidos en realidad lo que están haciendo es una objeción moral a su época. Y esa objeción es la misma que se le podría hacer a Shakespeare, Dostoievski, Wagner o Hitchcock.

No cabe, por tanto, despreciar de entrada y sin un análisis previo las formas y fondo de los contenidos de la producción televisiva nacional, porque, por ahora, han demostrado ser el mejor y más eficiente vehículo de la representación popular, emulando el trabajo de Shakespeare hace más de cuatrocientos años.

\section{Lenguajes shakesperianos y ecuatorianos}

Shakespeare no solo inventó personajes arquetípicos de la narrativa occidental, sino que también encontró insuficiente el inglés disponible e inventó palabras y frases que hoy son de uso cotidiano. El periodista inglés Henry Bernard Levin enumeró algunas de estas reinvenciones del lenguaje: está en chino (It's greek to me), recordar los años mozos (recall you salad days), se esfumó en el aire (vanished into the air), se trabó la lengua (tongue-tied), iOh, Señor! (Oh, Lord!), iVaya, vaya! (Tut, tut!), iPor el amor de Dios! (For Godness' sake!).

Salvando las distancias de léxico y sublimación del lenguaje, hay personajes televisivos ecuatorianos que también han logrado imponer palabras y frases que han quedado impregnadas en la conversación popular como iel turuleque! del Marciano Sabrosonix, iel amor, comprensión y ternura! de En Carne Propia, el ¡Esa es los muchachos! de la Mafia Chumi o el iqué reca! De Moti y Pescado.

Estas reinvenciones y apropiaciones del lenguaje en la cotidianidad ecuatoriana son otro elemento que da cuenta de la enorme vinculación histórica entre la obra de Shakespeare y varios programas de la televisión nacional en la construcción de lo popular. Aunque estas lecturas puedan ser frecuentemente distorsionadas, solo supone un paso natural en la dialéctica literaria, como Bloom señala: "cualquier gran obra literaria lee de una manera errónea -y creativa-, y por tanto malinterpreta, un texto o textos precursores". (Bloom, 1994, p. 18).

Pero, desde luego, los alcances poéticos de lenguajes de Shakespeare son mucho más amplios que la creación de modismos. Si de algo hemos de acusar al poeta es justamente de la belleza de sus textos dialogados. Esa cacofonía de voces que desbordan pasión mientras reflexionan sobre el mundo, expresan miedo, deseo, o incluso, cuando insultan.

Cuando el Rey Lear, en la Escena II del Acto Segundo, ha sido desterrado del reino por sus dos hijas, Goneril y Regan, indignado se compadece de sí mismo y las maldice: 
Aquí me veis, dioses, un pobre viejo, tan lleno de dolor como de años, miserable en ambas cosas. Si sois vosotros los que movéis los corazones de estas hijas contra su padre, no me hagáis tan estúpido como para soportarlo en paz. Tocadme de noble ira, y no permitáis que armas femeniles, gotas de agua, manchen mis mejillas de hombre. No, brujas desnaturalizadas, yo haré tales venganzas contra vosotras que todo el mundo... Haré cosas tales... No sé todavía cuáles son, pero serán los terrores de la tierra...

Durante el Noticiero al Cierre de TC Televisión del miércoles 25 de septiembre de 2019, el periodista Jonathan Carrera, relata el asesinato de un joven trabajador.

Se rompe el alma de amargura. Y vacío el cubículo donde Fredy trabajaba se ve más solitario que nunca porque falta el amigo, el colega, el caballero al que todos en el trabajo mucho lo apreciaban...Y si en el trabajo se siente su vacío, en su hogar el espíritu decae y las palabras quedan a medio pronunciar... Miserables como nadie miles, malos, infaustos, lo dejaron en el piso desangrándose malamente... Ese vacío que queda no se llenará jamás, y justicia es el grito desesperado, para que los asesino sean capturados y paguen su vileza en la prisión.

El relato de Carrera, empieza por describir el enorme daño causado. Lear queda pobre y solo. La nostalgia de que lo que fue ya no será. Lear ya no disfrutará de su reino, y el puesto de la víctima del asesinato, queda vacío, imposible de llenar.

Cuando Lear empieza a maldecir a sus hijas, y a direccionar su odio, se queda con palabras a medio pronunciar. Luego, el insulto, brujas desnaturalizadas, como malos infaustos, no acepta contención, para finalmente invocar, con un grito desesperado venganza o justicia, en un caso pidiendo captura y prisión, y en el otro, los terrores de la tierra. "Una nueva me- táfora, o una figura retórica inventiva, siempre implica partir de una metáfora previa" (Bloom, 1994).

El contenido de ambos textos es similar no sólo en fondo, sino en forma. Pareciera que las palabras que salen de la furia del Rey Lear son simplemente maquilladas por Jonathan Carrera. En tanto el discurso es el mismo, el lenguaje también. "El discurso instala, define y gobierna el modo como se puede hablar y razonar acerca de un tópico" (Hall, 1997, p. 469).

El estilo renacentista shakespeariano, desenfrenado, libre e incontenible, es imitado en los apasionados monólogos de los personajes telenovelescos que juran venganza o amor eterno con una verborrea desbordada y llena de florituras o en las descripciones descarnadas de la muerte en los programas de crónica roja.

Este trabajo de replicar a Shakespeare no puede ser nunca un problema de plagio, sino de reapropiación lingüística.

\section{La misma historia de siempre}

Si del lenguaje persiste una huella aplastante, de las estructuras narrativas, de las historias que se cuentan una y otra vez en la televisión ecuatoriana, es imposible no ver al fantasma de Shakespeare merodeando. Aunque Aristóteles, en su Poética, podría resolverlo todo a través de las ecuaciones que se aplican en el modelo clásico de narración, que ciertamente está presente a lo largo de Shakespeare y los programas de tv, hay una bacteria mucho más agresiva que ha liberado el dramaturgo británico en términos de cómo se cuenta el amor, la felicidad, el odio o el poder.

Aristóteles, que dice que el fin de la poesía es imitar y que la poesía es más fi- 
losófica que la historia, define las dos corrientes narrativas definitivas: tragedia y comedia. De la tragedia apunta que tiene como objetivo enaltecer los rasgos y las cualidades de los hombres reales. Busca, a través de esto, provocar temor o compasión en el público. En las tragedias, el héroe toma acción, por lo tanto, hay drama. La comedia, como oposición, es entonces una imitación de hombres inferiores, que encarnan vicios y que no toman acción. Busca provocar risas y se desarrolla en espacios cotidianos.

Aunque las definiciones aristotélicas permiten distinguir conceptos, también es cierto que tragedia y comedia pueden convivir en una misma narración siempre que cumplan su función legitimadora. En ese territorio, aparentemente limitado en posibilidades estructurales, pues cualquier obra siempre terminaría por entrar en alguna de las dos categorías, Shakespeare logró crear subcategorías más específicas. ¿Qué, si no una sitcom, es Sueños de una Noche de Verano? ¿Cómo no categorizar a Romeo y Julieta de romance? ¿o a Hamlet de un thriller?

Sharon la hechicera, empieza con una imagen fantasmagórica de Edith Bermeo, la estrella de música popular fallecida en 2015. Su fantasma, que atraviesa el tiempo, exige que se cuente una historia que dejó varios enigmas que necesitan ser resueltos. Esto da inicio al relato de la novela, como el espectro de Hamlet en la Escena V del Primer Acto da inicio a una de las obras centrales de Shakespeare.

Hamlet, tras escuchar a su padre, emprende su búsqueda por la verdad y la venganza prometida. Aunque dentro de la ficción, Samantha Grey, hija natural de Edith Bermeo y su intérprete en la novela Sharon, la hechicera, también busca res- puestas y cobrar cuentas en el relato televisivo de su madre.

Sharon es una joven talentosa y malhumorada que rechaza repetitivamente a sus pretendientes que la ven como un cuerpo, y toda su existencia se reduce al sexo, tal como le pasa al personaje de Isabel en Medida por Medida. El cuerpo y la virginidad de Isabel pueden salvar o acabar vidas, sin embargo, aunque grite "justicia, justicia, justicia", Angelo, su violador, concluye la conversación sosteniendo que nadie le creería. Entonces, como a Sharon en sus inicios artísticos y en su muerte, lo único que le queda a Isabel es el silencio.

Como denuncia o espectáculo, la conciencia de dominación patriarcal es inevitable en Shakespeare y en Sharon la Hechicera. En ambos casos, la mujercuerpo quiere hablar, pero le es negado el permiso.

Las relaciones de pareja, por su parte, están sometidas a los vicios del amor. Presuntamente, a nivel ficcional y judicial, el móvil del asesinato de Edith Bermeo son los celos de su pareja, tal como lo hace Leontes a su esposa Hermonio en Un Cuento de Invierno, y Othello a Desdémona en la Escena II, Acto V.

Ah, mujer perjura, me haces de piedra el corazón, y me haces llamar lo que pienso hacer asesinato, cuando yo lo consideraba sacrificio.

Las historias de Sharon, Leontes y Othello terminan por convertirse y verse como historias de amor imposibles, como en Romeo y Julieta y en La Pareja Feliz, aunque los oponentes difieran.

En Romeo y Julieta el antagonista son las relaciones sanguíneas, pero también su edad. Para el amor de La Pareja 
Feliz, sino la edad, al menos el tiempo, imposibilita la continuación de ese amor.

Mientras que Romeo y Julieta deciden poner fin a sus vidas, porque su amor no puede continuar en este tiempo y en este mundo, en La Pareja Feliz, con una sencilla elipsis de tiempo, ese amor puro e inocente se esfuma. Su continuación, desde luego cómica, viciada, con carnes deformes y violencia, son la confirmación del final del amor. Fueron Romeo y Julieta, pero el tiempo los envenenó.

En los dos casos de estudio de programas ecuatorianos, como en gran parte del universo shakespeariano, el amor es un proceso que está más allá de las relaciones, explica la existencia misma de los sujetos.

En la otra orilla, El combo amarillo y Mi Recinto, son ejemplos de costumbrismo, pero también de accionar colectivo, ejercicio del poder, roles de género y conflictos de clase y raciales. Perfectamente podríamos identificar a Cristhian Miranda, dueño de la cooperativa de taxis en El Combo Amarillo y a su esposa Estrellita, con Macbeth y Lady Macbeth, donde el señor, ambiguo y con culpas, es un tirano represor.

Este ejercicio de poder se entremezcla con situaciones disparatadas, como en Sueño de una Noche de Verano o en La Comedia de las Equivocaciones pero, eventualmente, hay momentos de catarsis colectiva.

En Mi Recinto, Garañón, personaje principal de la teleserie, busca permanentemente la unidad del grupo. Construye, desde la retórica, una familia que, si se lo dispone, podría ir a cualquier guerra para protegerse unos a otros y prosperar, similar al discurso de Enrique en Enrique V.

Estas comunidades dispuestas al sacrificio, de hermanos, amigos o familia, son transversales en la obra de Shakespeare, como lo son el equipo rojo o el equipo azul en Combate, o los clanes familiares en Tres Familias. En el segundo caso, además agravado por roles de clase donde las familias proyectan sus valores fundamentales en función de su condición económica. Así, la familia rica PlazaLagos no tiene que preocuparse por la economía, y sí mucho por las relaciones sociales, los Vaca-Galindo, ahorradores contumaces que quieren ascender en la escala social, y los Tomalá-Cabeza preocupándose por el pan de cada día.

Los paralelismos estructurales y discursivos de la obra de Shakespeare permean casi toda la producción de televisión nacional, no tanto como repeticiones sino como reinterpretaciones y giros morales adaptados a las circunstancias sociales del siglo XXI, que incluyen también el problema de la raza, el cholo y el moro, y de clase, el rico y el pobre.

\section{Conclusiones}

El impacto de los contenidos audiovisuales televisivos en la consolidación de discursos, en lo que se habla o no en una sociedad, en los lenguajes cotidianos y en la formación de identidades es indiscutible. La televisión, a pesar de los enormes avances de las plataformas digitales, sigue siendo el primer espacio de encuentro y discusión en el Ecuador y tiene tanta credibilidad como cualquier otra instancia o fuente comunicativa disponible. A pesar de su poderosa influencia, se la sigue tratando de una forma despectiva. Sus contenidos son maltratados y frecuentemente menospreciados en los círculos académicos e instituciones cultu- 
rales. La pregunta es, ¿se pueden hacer mejores contenidos?

Desde luego, en el aspecto técnico y narrativo, lejos está el Ecuador de producir contenidos del nivel de Hollywood, Europa, México o Colombia, aunque su actualización es inminente. Pero, evidentemente, la discusión no circula alrededor de estos tópicos, sino que tiende a detenerse en cuestiones morales, en un rechazo flagrante a estas manifestaciones, ciertamente populares.

Shakespeare, padre del canon occidental, genio máximo de la literatura universal, goza de un prestigio sin parangón. Sus obras, comedias, tragedias, poemas o sonetos, son enmarcados, casi sacralizados en bibliotecas, museos y universidades. No hay oposición a la difusión de sus carnales, violentas y espectaculares creaciones. Los niños van alegremente a ver El Rey León, adaptación de Hamlet, acompañados de sus padres, y el cuento de Romeo y Julieta atraviesa el imaginario nacional sin pudor alguno. Pero es tajantemente repudiado el acceso libre a $M i$ Recinto o En Carne Propia.

Este doble standard para medir las obras es realmente peligroso. La función del teatro de Shakespeare tiene poco que ver con la virtud cívica o la justicia social. No tiene teología, ni metafísica, ni ética, y mucho menos ideas políticas (Bloom, 1994, p. 66). Lo que no se le exige a Shakespeare se le exige a los creativos y productores nacionales. $\mathrm{Y}$, al no lograrlo - porque tampoco es su intención intentarlo-, se los termina demonizando como promotores de las malas costumbres. $\mathrm{Su}$ creatividad, sagacidad y conexión con el mundo de lo popular es, en cambio, raramente valorizado.

Lo problemático, en todo caso, no es la baja opinión que puedan tener los analistas, sino el constante intento de deslegitimación que sufren. El periodista César Ricaurte, en un artículo publicado en El Universo a propósito del programa Mi Recinto, se pregunta si se puede hacer comicidad sin conocer aquello que se caricaturiza. A lo que responde, que el programa "posee estereotipos que son un despropósito total: violencia sexual y agresión a la mujer, uso de las armas de fuego descuidado y sin razón y, por último, el racismo" (Ricaurte, 2006).

Retomando la disertación de lo popular de Yépez, este tipo de discursos quieren evitar que se visibilice el rompimiento de grietas, porque para quienes defienden este tipo de posiciones, lo popular simplemente no puede considerarse culto, justamente porque lo culto es una de las banderas con las que se defienden distinciones sociales que se perderían al incluir a lo popular en el mundo estético (Yépez, 2012).

No se puede desconocer estos rasgos apuntados por Ricaurte en Mi Recinto, como tampoco en Ecuador Tiene Talento, El Combo Amarillo, Combate, Vivos o 3 Familias. Pero tampoco en Hamlet, La Fierecilla Domada, Macbeth, Tito Andrónico o Romeo y Julieta.

Ni Shakespeare, ni los productores de Mi Recinto, son montubios o daneses, ni mercaderes o taxistas. La representación es un juego de convivencia entre la realidad y las metáforas.

Sólo en la auténtica legitimación de la producción televisiva nacional podremos sostener una discusión amplia, que involucre y no utilice y menosprecie a los sujetos representados y representadores. Que asuma sus lenguajes, sus deseos, sus miedos y sus perversiones. El gran enigma de Shakespeare no es su talento ni su sublimación del mundo, tampoco sus perso- 
najes o estructuras, sino su capacidad de hacer convivir el bien y el mal. En conectar con ricos y pobres, negros y blancos, hombres y mujeres y trans y etcétera.

William Shakespeare, cuatro siglos después de su muerte, está presente cada día a cada hora en la programación de los canales locales. Está en los personajes, las palabras, las estructuras, los chismes, los asesinatos, las intrigas, las traiciones, las caricaturas, los insultos, los besos, los prejuicios. Talvez también, para que podamos entenderlo mejor, $\mathrm{y}$ por consecuencia a sus hijos, Mi Recinto,
El Combo Amarillo, BLN, Combate, Vivos, Yo Soy, La Virgencita, En Carne Propia, En Corto, La Mofle, 3 Familias, De Boca en Boca, Yo Me Llamo, Ecuador Tiene Talento, etc., es necesario tomárselos un poco menos en serio. A fin de cuentas, como dijo Macbeth (Escena $\mathrm{V}$, Acto V):

La vida es sólo una sombra caminante, un mal actor que, durante su tiempo, se agita y se pavonea en la escena, y luego no se la oye más. Es un cuento contado por un idiota, lleno de ruido y furia, y que no significa nada. Entra el Mensajero.

\section{Bibliografía}

Álvarez, R. (2013). The Wire Toda la Verdad. Principal de los Libros. Barcelona. España.

Aristóteles (2013). Poética. Alianza Editorial. Madrid. España.

Barthes, R. (1974). El Placer del Texto y Lección Inaugural. Siglo XXI Editores. México.

Benjamin, W. (1989). Discursos Interrumpidos I. Taurus. Buenos Aires. Argentina.

Bloom, H. (1994). El Canon Occidental. Anagrama. Barcelona. España.

Deleuze, G y Guattari, F. (2002). Capitalismo y Esquizofrenia. Mil Mesetas. Pretextos. Valencia. España.

Fernández, C., J. C. Revilla y R. Domínguez (2011). Las emociones que suscita la violencia en televisión. Comunicar №36: 95-103.

Fernández, C., J. C. Revilla y R. Domínguez (2011). Identificación y especularidad en los espectadores de violencia en televisión: una reconstrucción a partir del discurso. Comunicación y Sociedad Vol. XXIVN¹: 7-33.

Freire, I. (2014). Análisis de las prácticas de mujeres docentes universitarias en entornos con discursos masculinizantes, Tesis de Maestría, Quito, Ecuador.

Freire, I. y Castillo, A. (2016). Las comedias de situación (sitcom) producidas por la televisión ecuatoriana y los estereotipos de género. Chasqui, no 131, pp. 383-400.

Galán, E. (2006). Personajes, estereotipos y representaciones sociales. Una propuesta de estudio y análisis de la ficción televisiva. En: ECO-POS, pp. 58-81.

García Canclini, N. (2006). El consumo cultural: una propuesta teórica. En El consumo cultural en América Latina, de GuiIlermo Sunkel, 72-95. Colombia: Convenio Andrés Bello.

González Castro, V. (2004). Para entender la Televisión. Editorial Félix Varela. La Habana.

Gordillo, I (2007). Viejos y nuevos formatos en la televisión del siglo XXI. Chasqui, no 99, pp. 66-71.

Hall, S. (1997). Representation: cultural representations and signifying practices. Sage Publications. Londres. 
Imbert, G. (2004). La tentación del suicidio: representaciones de la violencia e imaginarios de muerte en la cultura de la posmodernidad. Editorial Tecnos. Madrid. España.

INEC. (2012). Encuesta del Uso del Tiempo. http://www.ecuadorencifras.gob.ec/uso-del- tiempo-2/.

Jakobson, R. (1975). Ensayos de Lingüística General. Seix Barral. Barcelona.

Levi-Strauss, C. (1978). Antropología Estructural. Paidós. Barcelona. España.

Lyotard, J (1987). La Condición Postmoderna. Ediciones Cátedra. Madrid. España.

Marché, S. (2014). Cómo Shakespeare lo Cambió Todo. Penagos. México D.F. México.

Miramón, M. (2013). Michel Foucault y Paul Ricoeur: dos enfoques de discurso. La Colmena, no 78, pp. 53 -54.

Ordóñez, G. (2013). La Narrativa del Amor y la intimidad en una serie de Televisión. Corporación Editora Nacional. Quito. Ecuador.

Pachano, S. (2003). Antología Ciudadanía e Identidad. FLACSO. Quito. Ecuador.

Panchi, M. (2013). La Estética de la Transgresión: Análisis y Dinámicas del Sensacionalismo en la Televisión Ecuatoriana. FLACSO. Quito. Ecuador.

Thompson, J. (1998). Los Media y la Modernidad. Paidós. Barcelona. España.

Rancière, J. (2010). El espectador emancipado. Ediciones Manantial. Buenos Aires. Argentina.

Redondo, M. (2011). El sensacionalismo y su penetración en el sistema mediático español. Valladolid. España.

Ricaurte, C. (2005). ¿Se puede hacer comicidad sin conocer aquello que se caricaturiza?, El Universo, Ecuador 22 de enero, 2006.

Shakespeare, W. (1994). Shakespeare Tragedias. Editorial Planeta. Barcelona. España.

Superintendencia de Telecomunicaciones del Ecuador (2015). Plan Nacional de Desarrollo de Banda Ancha. Ministerio de Telecomunicaciones y Sociedad de la Información. Recuperado de: www.telecomunicaciones.gob.ec/ plan-nacional-de-desarrollo-debanda-ancha/

Vallejo, E. (2016). Representaciones Sobre la Población Afroecuatoriana en la Comedia de Televisión Ecuatoriana. (Tesis de Maestría). FLACSO. Quito. Ecuador

Yépez, S. (2012). Estéticas Populares, Estrategias de Impugnación y Construcción de la Identidad desde la Música de Delfín Quishpe. Universidad Andina Simón Bolívar. Quito. Ecuador.

Zizek, S. (2003). El Espectro de la Ideología. FCE. Buenos Aires. Argentina. 